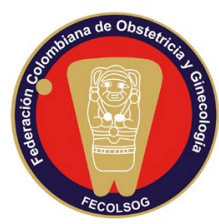

\title{
La Revista Colombiana de Obstetricia y Ginecología ahora también en PubMed Central
}

\author{
Hernando Gaitán-Duarte, MD, MSc ${ }^{1}$; Luz Ayda Becerra-Reyes, $M S c^{2}$
}

on inmenso orgullo queremos compartir con nuestros autores y lectores que el día 6 de julio de 2021 recibimos la confirmación, por parte de la US National Library of Medicine, de la aceptación de la Revista Colombiana de Obstetricia y Ginecología (RCOG) en la base de datos Pubmed Central (PMC), que nos permite asegurar la preservación a largo plazo y el acceso libre al contenido de la Revista desde este repositorio.

La admisión de la RCOG a PubMed Central (PMC) es motivo de satisfacción para el equipo editorial que se ha venido consolidando durante los últimos años, y que acompañó de manera cercana el proceso de postulación a este reconocido repositorio digital de contenido (artículos) de revistas en ciencias de la salud. Esta es la continuación de un proceso que se consolidó en el año 2019 con la aceptación en Medline, en busca de incrementar la visibilidad de la RCOG, ventana de los estudios realizados por investigadores de Colombia e Iberoamérica, que abarcan todos los aspectos de la salud de la mujer, con énfasis en la salud materna y perinatal, y aquellos que afectan los derechos individuales y colectivos de las mujeres relacionados con la salud, a partir de diferentes aproximaciones metodológicas.

Ahora la RCOG es parte de un selecto grupo de revistas colombianas incluidas en PubMed y Pubmed Central, tales como Investigación y Educación en Enfermería, Colombia Médica y Biomédica (1).

Con la intención de animar a otras revistas colombianas a conseguir estos estándares de excelencia,

1. Revista Colombiana de Obstetricia y Ginecología (RCOG), Bogotá (Colombia). 2. Biteca SAS, Bogotá (Colombia). mencionaremos los pasos que se requieren para lograr la aceptación a PMC:

1. Aplicación inicial: envío de formulario donde se solicita información general de la revista, desde datos básicos, políticas editoriales y, en general, el tipo de prácticas editoriales establecidas. Esta información debe ser visible en la página web de la revista o plataforma de publicación.

2. Evaluación inicial de la aplicación: una vez enviado el formulario, el equipo de PMC verifica la información y, de ser necesario, comunica cualquier tipo de inconsistencia o inquietud a fin de que sea solucionada por parte del solicitante.

3. Evaluación de la calidad: se valora, con base en ciertos parámetros, si la revista cumple con los criterios de calidad exigidos por PMC.

4. Evaluación técnica: en esta última fase del proceso se evalúa el contenido que se pretende publicar en un formato específico (XML), que debe disponer de características concretas para ser compatible con la plataforma de publicación PMC.

5. Fase de preproducción: en esta fase se solicita a la revista el envío del acuerdo firmado por el representante legal de la entidad editora, y el paquete total de los artículos que se van a publicar con el protocolo XML JATS y los logos e imágenes representativas de la revista.

6. Por último, el contenido se publica en el repositorio que queda disponible para el público en general (2). 
Vale la pena recordar que los criterios para permanecer tanto en Medline como en PMC, tales como cumplir con las mejores prácticas editoriales, transparencia e integridad científica, adherencia a los estándares de COPE, DOAJ, WAME y OASPA, así como continuar con los altos estándares de calidad científica, editorial y técnica ya logrados, los cuales se evalúan y revisan constantemente. Invitamos, pues, a los investigadores interesados en publicar en la RCOG a adherir a este proceso editorial cada vez más exigente, que inicia con la verificación de requisitos para la aceptación, el seguimiento de las instrucciones a los autores sobre cómo publicar los diferentes tipos de manuscritos, y hacer la traducción al inglés para que las investigaciones alcancen una mayor audiencia y, de esta manera, reducir la dependencia científica en que nos encontramos.
Queremos agradecer a Biteca SAS, como empresa colaboradora de la RCOG, por este nuevo logro que permite que nuestro contenido sea recuperado por los investigadores y lectores en la plataforma de PMC.

\section{REFERENCIAS}

1. US National Library of Medicine. National Institutes of Health. PMC Journal List [A-B]. 2021. Disponible en: https://www.ncbi.nlm.nih.gov/pmc/journals/

2. US National Library of Medicine. National Institutes of Health. How to Include a Journal in PMC. 2021. Disponible en: https://www.ncbi.nlm.nih.gov/pmc/ pub/addjournal/ 